\title{
Habitat Selection and Phenology of the Fiji Tree Frog, Platymantis vitiensis: Implications for Conservation
}

\author{
Tamara Osborne, ${ }^{1,2}$ Clare Morrison, ${ }^{3}$ and Craig G. Morley ${ }^{1}$ \\ ${ }^{1}$ Biological Sciences Division, Faculty of Science and Technology, University of the South Pacific, Suva, Fiji \\ ${ }^{3}$ Institute of Applied Sciences, University of the South Pacific, PO Box 1168, Suva, Fiji
}

\begin{abstract}
Авstract.-Macrohabitat and microhabitat preferences of the endemic Fiji Tree Frog Platymantis vitiensis were investigated in Savura near Suva, Viti Levu, Fiji. Twelve sites in three habitat types (primary rain forest, disturbed secondary rain forest, and mahogany plantations) were surveyed from June 2004 to May 2005. The phenology of $P$. vitiensis was also studied along two permanent transects (adjacent to, and distant from, a stream bank) within the Savura area. Individuals were more abundant in primary rain forest than mahogany plantations and secondary rain forest. Individuals were common along stream banks, perched on riparian plants such as Pandanus, ferns, and Dolicholobium (and usually found 100-200 cm above the ground). Rainfall influenced activity, with fewer individuals observed during intense rainfall events. Adult frogs were more frequently encountered between July and October and gravid females between August and November. Hatchlings were more common during the dry season (May to October), whereas juvenile abundances peaked early in the wet season (November to April). Future surveying and monitoring of $P$. vitiensis populations should be conducted during March to July, when abundances are greater. The efficiency of rapid surveys can be maximized by subsampling along riparian vegetation, particularly where Pandanus are present.
\end{abstract}

The Fiji Tree Frog, Platymantis vitiensis, is one of two endemic ranid species found in the Fiji archipelago, the other being the Fiji Ground Frog, Platymantis vitianus. The range of $P$. vitiensis is thought to have extended throughout the western and central parts of the Fiji Island group before human arrival (Gorham, 1968; Pernetta and Goldman, 1977), but its distribution is now restricted to just four of the largest islands (Morrison, 2003): Viti Levu, Vanua Levu, Taveuni, and Ovalau.

Platymantis vitiensis was recently recategorized as "near threatened" on the IUCN Red List because of increasing habitat alteration and loss (Zug et al., 2004). At a time when global trends indicate extensive and rapid declines in tropical amphibian populations (attributed to habitat loss and alteration), it has become imperative to fully understand the links between threatened amphibians and their habitats. To estimate the threat of future habitat loss to extant $P$. vitiensis populations, we need to investigate the factors that influence population persistence.

The Fiji Tree Frog is considered to be strongly associated with riparian strips in "good" rain forest (Watling and Zug, 1998). Certain aspects of habitat structure (e.g., canopy cover) and other factors (e.g., plant species composition) are thought to play an important role in site

\footnotetext{
${ }^{2}$ Corresponding Author: E-mail: osborne.tamara@ gmail.com
}

selectivity of amphibians (Gregory, 1983). Canopy cover can limit the amount of sunlight filtering through to the subcanopy and forest floor vegetation, influencing air temperature within the rain forest and moisture levels in retreat sites (Beard et al., 2003).

Previous work on $P$. vitiensis has indicated an affinity for certain plant species (particularly riparian Pandanus spp.) as diurnal retreat sites (Gorham, 1971). The frogs can often be found sheltering during the day in the moist leaf litter that collects between the base of the Pandanus leaves and the plant stem (Ryan, 2000). Other habitat studies have documented strong associations between amphibian species and Pandanus (Alcala and Brown, 1982; Lethtinen, 2002) where several lifestyle activities, such as foraging and breeding, are conducted on these plants.

Platymantis vitiensis breed year-round but are considered more reproductively active between December and March, with a peak in breeding activity occurring in late February to early March (Gibbons and Guinea, 1983; Morrison, 2003). Eggs are relatively large with sufficient food storage to sustain direct development within the egg and are generally laid in the axils or branches of riparian plants (Ryan, 1984). Adult behavioral traits include evasive jumping, good swimming ability, and darkening during the day (to blend into the leaf litter). These characteristics have probably enabled the species to persist on islands in the Fiji group 
where predators such as mongoose (Herpestes javanica), rats (Rattus sp.), and cats (Felis catus) have been introduced. The reduction of their overall range has been attributed to the combined effects of habitat modification and fragmentation and introduced predators (Pernetta and Watling, 1978).

Literature concerning the ecology and reproductive phenology of $P$. vitiensis is generally anecdotal with only Gorham's (1968) fieldwork providing baseline data. By systematically recording abundance and activity patterns in an accessible population of the species, we aimed, for the first time, to develop effective sampling protocols for future studies and additionally to provide further information on phenology and habitat preferences. Such data are essential for the design of surveying and monitoring protocols for anurans (Parris and McCarthy, 1999; Parris, 2004).

\section{Materials and Methods}

The Savura and Vago Forestry Reserves (established in 1963 and 1959, respectively) are located approximately $10 \mathrm{~km}$ north of central Suva, Viti Levu. Access to the reserves is restricted and the area has never been commercially logged (Keppel et al., 2005). The major habitats within Savura are lowland and highland rain forest, with mahogany plantations and areas of secondary lowland forest on the periphery of the sites. An unsealed road runs northeast through the reserve, and several smaller tracks provide access into the forest and to the streams (Fig. 1). The study area has undulating ridges (altitudinal range 20-400 m), with steep slopes and narrow stream valleys, in which there are several narrow rapid streams that drain into a tributary of the Rewa River. The climate of the Fiji Islands is distinctly seasonal, with a warm and wet season during the months of November to April, and a cool and dry season from May to October. Rainfall data for the locality was obtained from the Fiji Meteorological Station in Laucala Bay. Rainfall for the 24- $h$ period was measured at the station at approximately $2100 \mathrm{~h}$ each night.

Surveys were conducted using a modified Visual Encounter Survey (VES) method (Heyer et al., 1994). Survey locations were carefully visually searched. Head lamps were used to "spotlight" individual frogs present on vegetation or the ground. Sites were searched between 1800 and $2300 \mathrm{~h}$ by a three-person team: one surveyed along the transect and two surveyed $5 \mathrm{~m}$ either side to form a "belt" transect. The vegetation was searched opportunistically for frogs hidden in leaf litter.
All individuals captured were placed in plastic click-seal bags and weighed with a $60-\mathrm{g}$ Pesola scale (1-g accuracy). The SUL (snouturostyle length) of each individual was measured using a vernier calliper (0.1 mm accuracy) and toe clipped to allow identification of recaptured frogs. Individuals were sexed where possible using indicators of mass, SUL, presence of a yellow groin flash, and presence of egg masses (observed through slightly transparent abdominal skin). Adult males were identified as individuals weighing 1.5-4.0 $\mathrm{g}$ and displaying the yellow groin flash. Adult females are reproductively mature at larger sizes and were identified by weight $(>4 \mathrm{~g})$. Adult females consistently do not display the yellow groin flash at smaller sizes like male frogs (pers. obs.). Hatchlings were identified as having hatched within three months of capture and below $0.7 \mathrm{~g}$ in body mass (Gorham, 1971; Ryan, 1984). Larger individuals that were not reproductively mature (no groin flash) and weighed between 0.8-1.5 g were classed as juveniles.

Broad-Scale Habitat Survey.-Primary lowland forests, secondary lowland forests and mahogany plantations were surveyed. The differences in structure and species composition between the three habitats were caused by human activity with increasing levels of disturbance from primary to mahogany to secondary forests. Introduced plant species were more prevalent in the mahogany and secondary forest types. In addition, canopy cover was less dense in secondary vegetation. Twelve sites in each of the three habitat types were surveyed over a 12month period spanning the two seasonal periods. One site per habitat was sampled each month and the sampling location within each habitat was selected to ensure that it was sufficiently distant from $(>100 \mathrm{~m})$ those sampled previously to be considered independent. Sampling occasions for each habitat were allocated randomly to avoid systematic bias in sampling sequence. Visual surveys were conducted for two hours on each sampling occasion along accessible lowland streams within each habitat. Microhabitat and environmental variables (plant species, height above ground, distance from stream, and air and stream temperatures in ${ }^{\circ} \mathrm{C}$ ) were recorded. Air and stream temperature was recorded at the start and end of each survey using a standard alcohol thermometer.

Abundance of frogs (recorded as total frog count sampling occasion ${ }^{-1}$ ) was used within an analysis of variance including the factors of habitat (plantation, secondary, mahogany) and season (dry, wet) to determine whether habitat influenced $P$. vitiensis distribution. Twenty-fourhour rainfall prior to sampling occasion was 


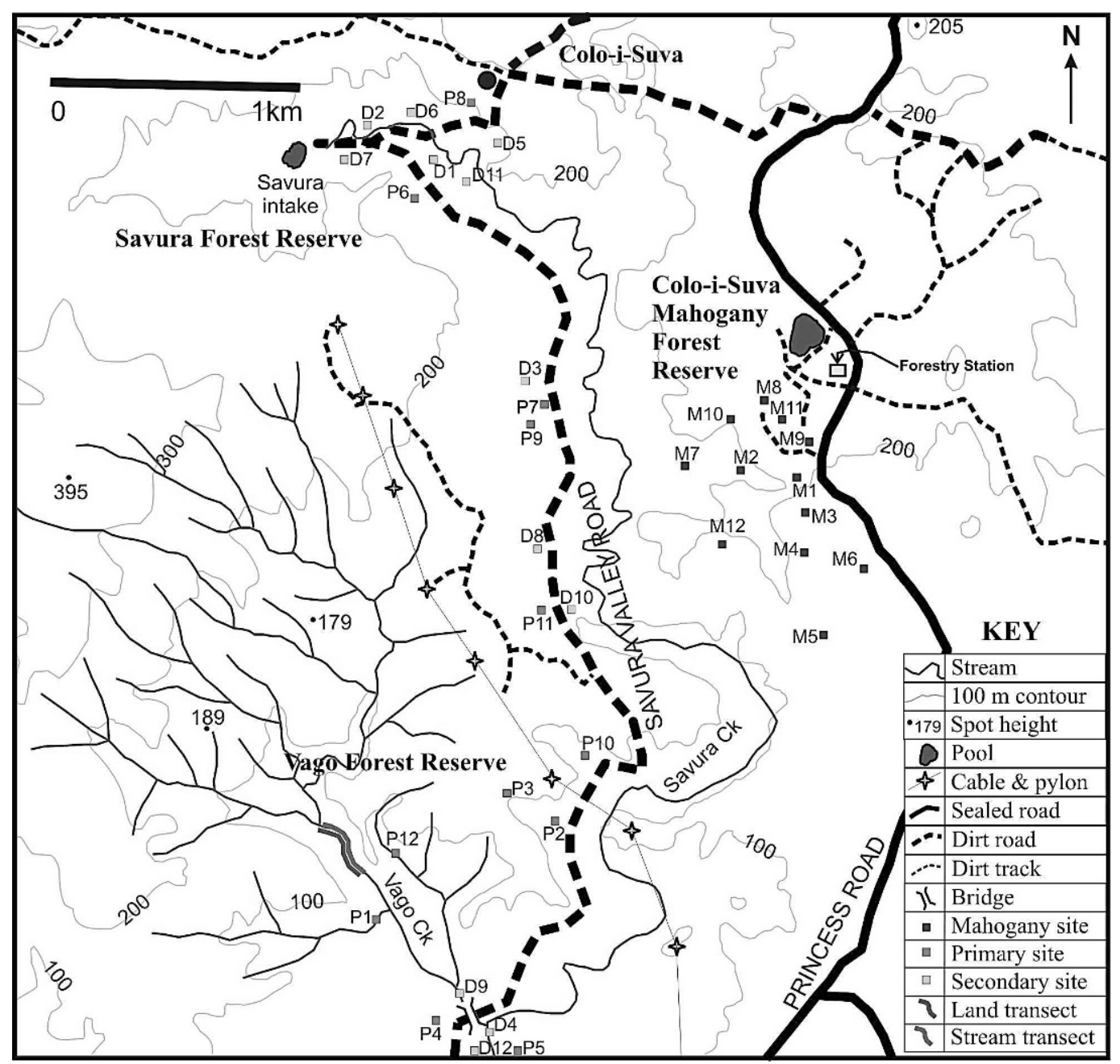

FIG. 1. Map of the study site showing general features such as elevation, hydrology, roads, reserves, and pylon lines.

used as a covariate as preliminary surveys indicated that short-term rainfall events strongly influenced frog activity. Count data were $\log _{10}(n+1)$ transformed to ensure equality of variance, which was tested prior to analysis by Levene's method. The relationship between the transformed counts and short-term rainfall was investigated by linear regression. All analyses described were conducted using SPSS Version 13.0 for Windows ${ }^{\mathrm{TM}}$.

Fine-Scale Survey.-Two 200-m permanent transects were established and marked out using rope and flagging tape along a major stream where frog activity had been previously observed. One was proximal to the stream and a second was parallel to the first, but positioned within the forest and separated by a 10-m buffer zone. These transects were sufficiently separat- ed to ensure minimal mixing of individuals sampled yet retained similar environmental conditions. Each 200-m transect was searched on each sampling occasion.

Transects were surveyed twice each calendar month for approximately $90 \mathrm{~min}$ active searching time, alternating direction each night. When an individual frog was observed, detailed microhabitat information was recorded. Information recorded included vegetation type (to species if possible) or substrate, distance to nearest stream, and perch height from the ground. Data were analyzed using an analysis of variance as for the broad-scale habitat surveys. Frog abundances recorded along the stream and land transect were compared using a paired $t$-test. Additionally, the composition of the frog population on each sampling occasion 


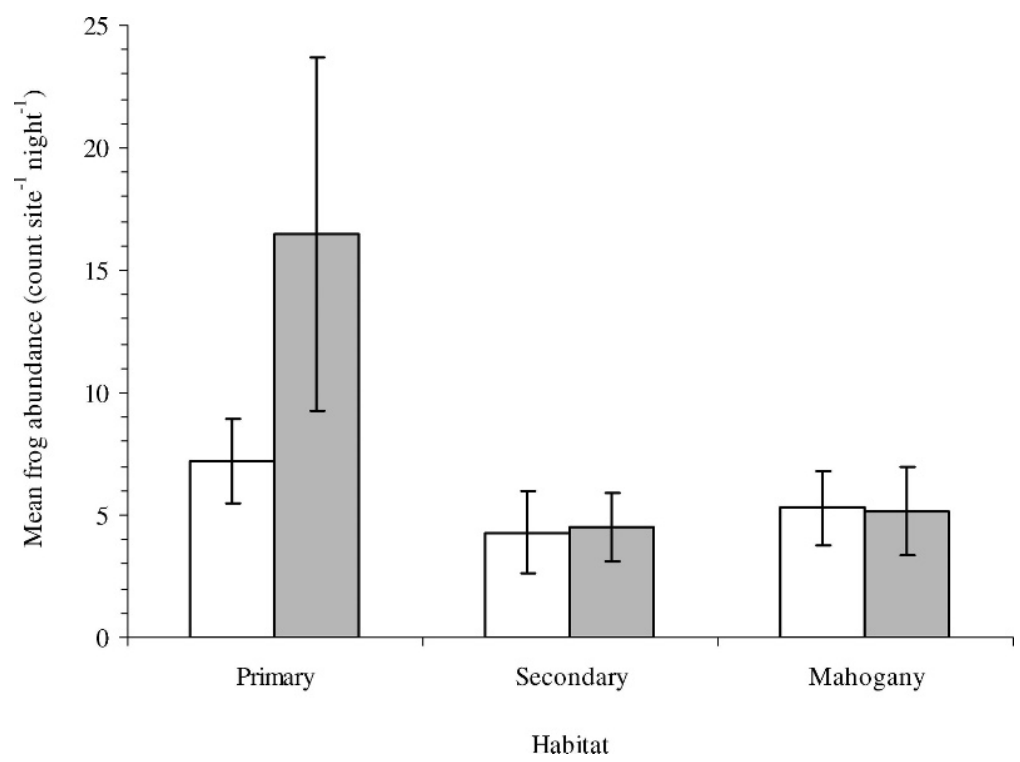

FIG. 2. Platymantis vitiensis abundance at Savura Reserve (mean count site ${ }^{-1}$ night $^{-1} \pm 1 \mathrm{SE}$ ) in three habitat types surveyed during the dry (shaded) and wet (unshaded) seasons.

was represented by the proportion of the population represented within each defined age class.

\section{Results}

Average air and stream temperatures varied over the two seasons. During the dry season, air temperatures ranged from $18-22^{\circ} \mathrm{C}$, whereas during the wet season air temperatures were between $25^{\circ} \mathrm{C}$ and $28^{\circ} \mathrm{C}$. Because the streams were narrow and shallow, stream temperatures were on average $1^{\circ} \mathrm{C}$ lower than the concurrent air temperature. Daily rainfall varied from $0.7-$ $104.0 \mathrm{~mm}$ in the wet season and $0-23.8 \mathrm{~mm}$ in the dry season.

A total of $144 P$. vitiensis was captured in primary lowland rain-forest sites, 53 in disturbed secondary lowland rain-forest sites, and 64 from mahogany plantations over the year (with a total of $24 \mathrm{~h}$ of survey time per habitat type). Abundance was measurably different between habitats $\left(F_{2,29}=3.9, P=0.031\right)$ : Primary forest had higher abundance compared to secondary and mahogany areas with approximately a $50 \%$ reduction evident for the year as a whole (Fig. 2). Season had no measurable effect on abundance $\left(F_{1,29}=1.7, P=0.196\right)$, whereas short-term rainfall $\left(\log _{10}[n+1]\right.$ transformed) significantly influenced abundance $\left(F_{1,29}=9.6, P=0.004\right)$. No interaction between season and site was evident $\left(F_{2,29}=\right.$ $1.0, P=0.37)$. Investigation of the relationship between rainfall (R) and abundance (A) by regression indicated a negative relationship between the two variables $(N=36, r=0.42, P$ $=0.012$ ). We also observed that on weeks when it rained every day leading up to the sampling night, fewer $P$. vitiensis were found. On several occasions when diurnal showers were particularly heavy, very few individuals were encountered that night.

Analysis of data collected from the fine-scale surveys indicated that the number of individuals encountered along the stream transect was significantly greater than the number of individuals encountered along the adjacent land transect $\left(t_{43}=-16.4, P<0.001\right)$, with a total of 372 along the stream and 276 along the land transect, respectively. Higher abundance along the stream transect was further confirmed by the analysis of variance $\left(F_{1,19}=5.0, P=0.038\right)$. Additionally, season had no measurable effect $\left(F_{1,19}=1.9, P=0.18\right)$, whereas short-term rainfall had a significantly negative influence on frog abundance $\left(F_{1,19}=13.9, P<0.001\right)$. Again no interactions were evident.

The majority of individuals were found on Pandanus (28\%), ground ferns $(12.6 \%)$, and Dolicholobium sp. (10\%). Syzygium seemannii (abundant along the Vago stream) was also a common perch plant along the stream transect. The majority of perch plants were low-lying herbs and shrubs ( $<5 \mathrm{~m}$ tall). Most individuals observed were found from $50-100 \mathrm{~cm}$ above the forest floor followed by $100-150 \mathrm{~cm}$ (Fig. 3). A relatively small proportion of individuals were observed close to the ground or at heights 


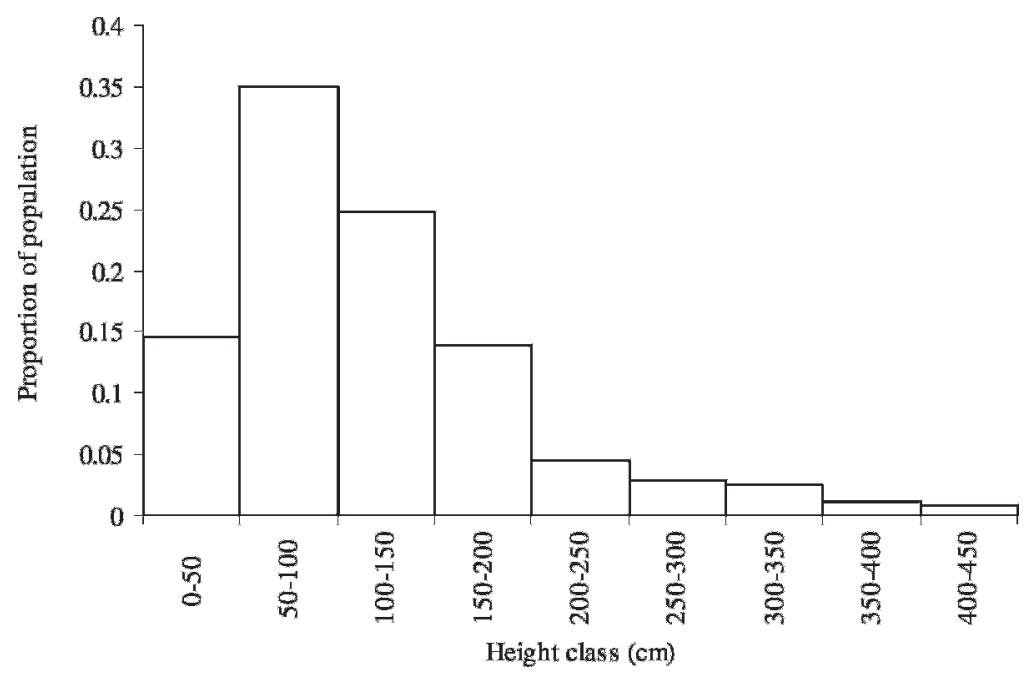

FIG. 3. Histogram of the proportion of Platymantis vitiensis individuals perched within the height category from the permanent fine-scale transects at Vago Stream.

exceeding $150 \mathrm{~cm}$. This distribution was significantly different from the null of an even distribution $\left(\chi_{9}^{2}=823.0, P<0.001\right)$.

Total counts of $P$. vitiensis were lower during the first part of the wet season (November to January), which may be caused by the effect of short-term rainfall events causing a reduction in activity on these survey occasions (Fig. 4). Adult frogs and hatchlings were represented in fairly consistent proportions (of the fixed transect sample) during the year (Fig. 5). The variability that was evident was probably caused by the effect of short-term rainfall events, particularly during the November to April wet season. However, gravid female abundance and to a lesser extent hatchlings showed distinct seasonal patterns in abundance (Fig. 5). Gravid females were more evident within the population from June to December, which spans the end of the dry season and the beginning of the wet. No gravid individuals were recorded toward the end of the wet season and the beginning of the dry. Hatchlings were more evident from the middle of the wet season, which corresponded with the disappearance of gravid females from the population. Hatchlings were represented proportionately less during the end of the dry season and the beginning of the wet.

Only two egg clutches were recorded in the 12 months of surveying in this entire study. The first clutch of 18 eggs was recorded in September 2004, in a Pandanus axil at a height of $0.6 \mathrm{~m}$ above the ground. The second clutch (about 10 eggs) was recorded in January 2005 at a height of about $1.5 \mathrm{~m}$ in the leaf litter at the base of branches of a Crossostylus seemannii sapling. It was notable that one egg clutch was recorded toward the end of the dry season, and the other was recorded mid-wet season. Higher metamorph abundances at the beginning of the dry season indicated that gravid females were laying eggs in the latter months of the dry season (given 4-5 weeks of embryonic development).

\section{DisCUSSION}

Platymantis vitiensis abundance was greater in primary lowland rain forest, compared to secondary lowland rain forest and mahogany forest habitats, respectively. Very low frog abundances have been recorded in secondary vegetation in other studies (Marsh and Pearman, 1997; Galindo-Leal et al., 2003), which is attributed to the loss of suitable microhabitats caused by changes in the forest structure and floral composition (Laurance et al., 2002). This study indicated that $P$. vitiensis was not restricted to primary habitat like many threatened species found in the New World tropics (Hero et al., 2005) because they were also recorded within the secondary and mahogany plantation areas (although the abundance was measurably lower). Their distribution may be limited by structural components of primary rain forest and possibly secondary formations (Parris and McCarthy, 1999; Fogarty and Vilella, 2003). Canopy cover, plant species composition, the density of understorey vegetation, and food availability, may affect distribution patterns and these factors warrant further investigation.

The negative relationship between $24-\mathrm{h}$ rainfall and abundance at the sites in the broad- 


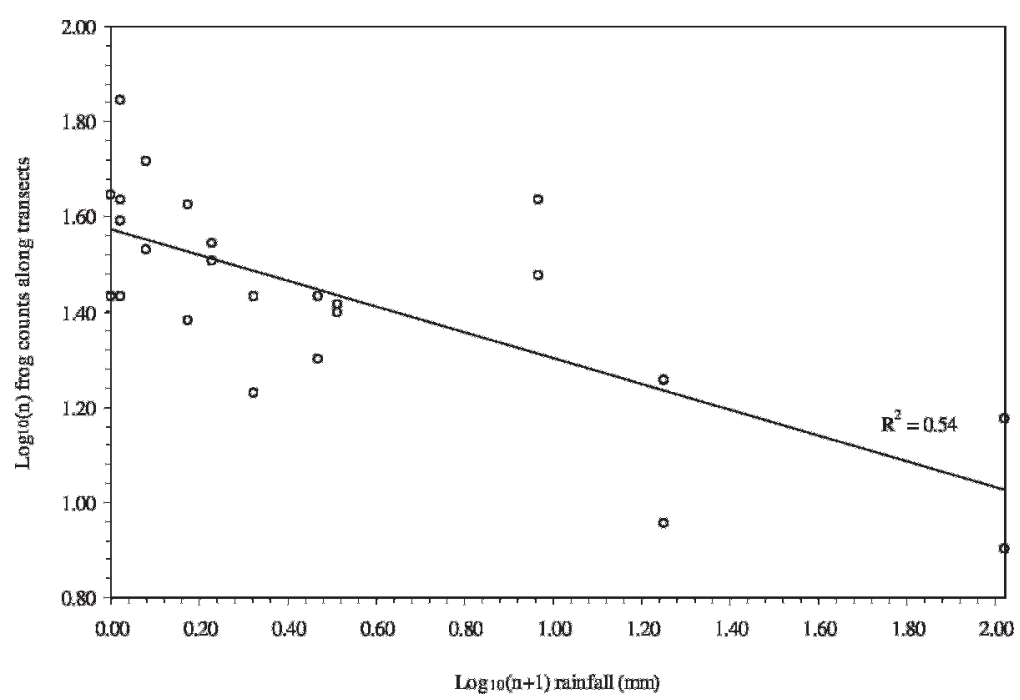

FIG. 4. Relationship between 24-h rainfall (millimeters) and transformed frog abundance ( $\left.\log _{10}[\mathrm{count}]\right)$ on survey nights along the permanent fine-scale transects.

scale survey indicated that rainfall is an important factor when conducting surveys. We found that fewer individuals were encountered when rainfall prior to and during a survey was high. A similar result was found by Marsh (2000) who found female Tungara Frogs (Physalaemus pustulosus) were less active on "wet" sampling nights. We attribute the correlation between higher 24-h rainfall and fewer $P$. vitiensis to a reduction in activity during intense rainfall events, as intense tropical rainfall events are likely to increase chance mortality for small individuals as well as decreasing the success of foraging for insect prey.

Platymantis vitiensis, like other arboreal anurans (Stewart, 1985; Galindo-Leal et al., 2003), were found in microhabitats with specific structural and ecological features, particularly height above ground and type of perch site. Another important spatial variable that appeared to influence activity was proximity to a stream channel.

Fiji Tree Frogs showed a strong affinity for sites proximal to streams as most individuals were found within $2 \mathrm{~m}$ of the stream in all habitats and along the stream transect. This may be a result of the greater abundance of flying insects in the open space of the riparian strip (Whitaker et al., 2000), where there would be a higher rate of feeding success during nocturnal foraging. As more individuals were recorded along the stream transect than the land transect at the Vago stream location, it is likely that individuals were preferentially selecting perch sites close to the edge of the stream. Plants often used as perch sites (e.g., Pandanus) by the Fiji
Tree Frog, in this study and previous work, are more common along the stream than within the forest (Parham, 1964; Ryan, 2000). However, the greater density of plants within a forest may have influenced visibility and, therefore, sampling abundances recorded.

Platymantis vitiensis individuals were mostly found on Pandanus spp. along streams and in flat marshy areas. Similar results were previously reported by Gorham (1968), Pernetta and Goldman (1977), and Ryan (1984). Most of the individuals, in this and previous studies, were found in the base of the Pandanus leaf axil, which collects leaf litter and rainwater, and it is clear that a strong association exists between rain-forest Pandanus plants and $P$. vitiensis. Other important species included low-lying ferns, aroids (Alocasia indica) and shrubs (Dilenia biflora, Ficus bambusifolia and Syzygium seemannii). A similar association with specific plant species has also been shown for Coqui frogs, Eleutherodactylus coqui (Beard et al., 2003). Ficus bambusifolia and $S$. seemannii flower between December and January, attracting flying insects during this time, which probably also attracted $P$. vitiensis to forage on these plants.

As moisture levels in their environment affects skin-surface respiration (Zug, 1993; Beebee, 1996), it is likely that individuals selected arboreal sites that retained some treeflow (rainfall that is intercepted by vegetation). Pandanus, D. biflora, and Dolicholobium are good examples of plants that retain tree-flow in their axils, sheathed petioles, and on leaf blades.

It is probable that increased risk of desiccation (on windy nights with low humidity and 


\section{Land Transect}

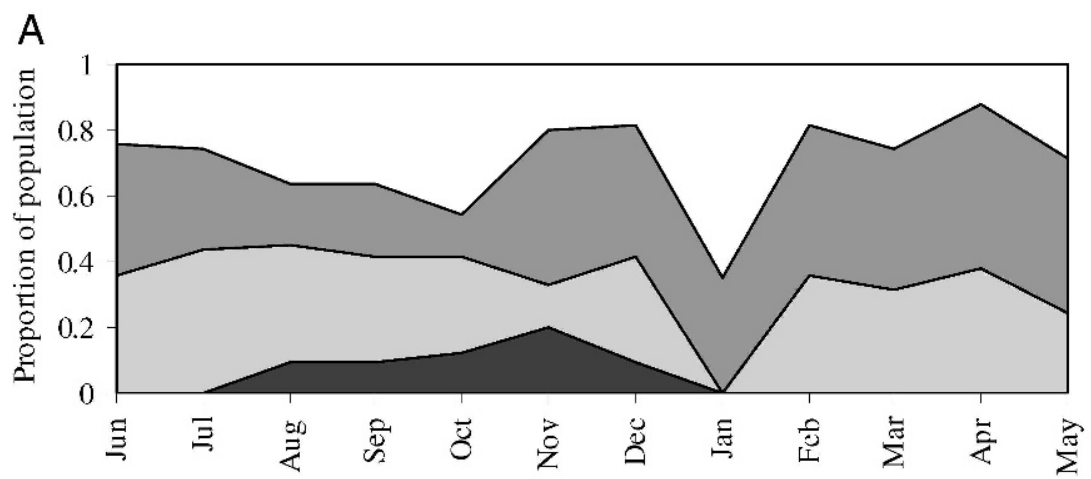

$\square$ Juveniles $\square$ Metamorphs

$\square$ Adults

$\square$ Gravid females

\section{Stre am Transect}
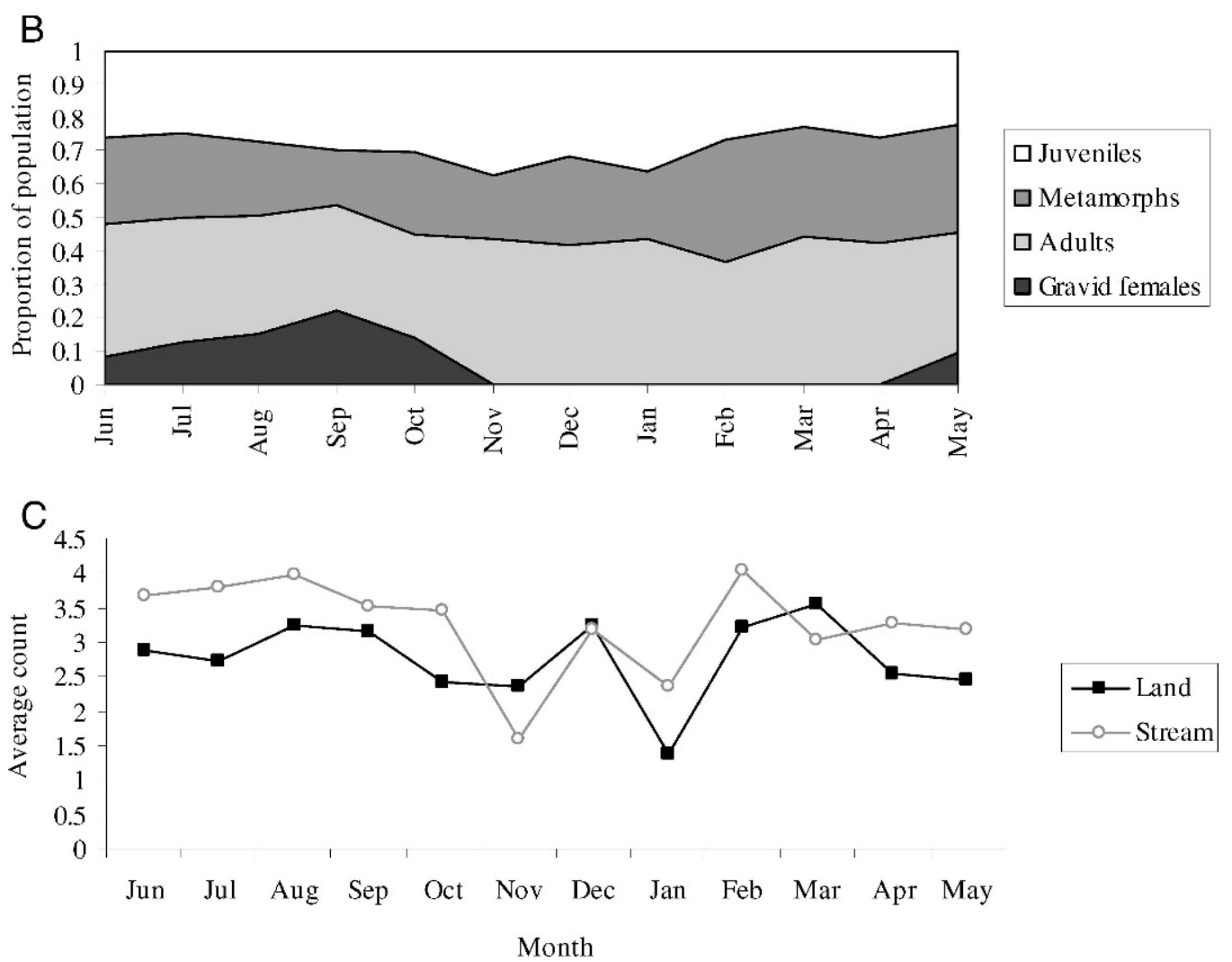

FIG. 5. Proportion of Platymantis vitiensis individuals in each age/sex (adult, gravid female, metamorph, juvenile) category over the 12-month survey recorded from the permanent land (A) and stream (B) transects, respectively. Average abundance (mean count transect ${ }^{-1}$ night $^{-1}$ ) for each month for each transect is also shown (C).

cool temperatures), or increased risk of mortality (on nights with heavy rainfall and high stream levels) may result in frogs temporarily abandoning certain perch sites. During periods of heavy rainfall, smaller individuals may abandon nocturnal streamside activity in favor of safer perch sites underneath the canopy of the forest. The influence of weather on perch 
and retreat sites of anurans has been reported previously (Ritke and Babb, 1991). Short-term (24-h) rainfall was an important variable in determining activity along the transects; rainfall patterns have been found to influence the microclimates of diurnal retreats and nocturnal perch sites of $P$. vitiensis by affecting the moisture levels in leaf litter and the moisture present on vegetation surfaces (Kam and Chen, 2000).

The phenology of the Vago Creek population showed complex patterns that may be a result of interannual fluctuations in weather, as well as other factors, such as migration and recruitment. The phenological pattern indicated in this study is much more distinct than previously thought. Although previous studies suggest that $P$. vitiensis breeds throughout the year, no gravid females were caught during the period of January to April. In addition, there was evidence of greater activity of gravid females toward the end of the end of the dry season/ beginning of wet, confirming anecdotal records of egg-laying (Morrison, 2003). Metamorph development may be longer than previously thought, as metamorph abundances were consistently represented in the population throughout the 12-month survey period. In total, more hatchlings were captured during the dry season whereas juvenile abundances were higher in the wet season. This may indicate a period of juvenile recruitment over the wet season months.

Understanding the distribution of Fiji's Platymantis is essential to the development of effective conservation programs. Long-term and short-term changes in population size are vital factors to consider when designing conservation projects (Biek et al., 2002). The conservation of both Platymantis species is necessary because of their endemicity, and Fiji's Platymantis represent an important branch of the genus and the generic genome. As $P$. vitiensis populations in Savura only show some preference for primary forest habitats, it is recommended that future surveys should not be restricted to primary lowland rain forest but should encompass secondary vegetation with moderate levels of human disturbance as well as plantation forest. Surveys that are time limited may increase efficiency by subsampling along riparian strips in forested areas, focusing on species such as Pandanus, Dolicholobium and ground ferns. Rapid surveying protocols could focus on surveying such locations and microhabitat features to estimate population size. To obtain more accurate estimates of adult population size, it is recommended that sampling be carried out between the late wet season to early dry season (approximately March to July).
Future research on Viti Levu to map extant $P$. vitiensis populations and to clarify the agents causing the extirpation of Fiji Tree and Ground Frogs is necessary for conservation purposes. In addition, it is suggested that past distributional patterns and the probable causes for the reduction in range of both species need to be investigated to allow for greater understanding of the extirpation events and enhance current conservation efforts for Fiji's Platymantis.

Acknowledgments.-This work was sponsored by NZAID and the University of the South Pacific. Thanks to occasional field volunteers; to N. Thomas, J. Kuruyawa, I. Rounds, J. Nuikula, T. Mulo, P. Pikacha, and V. Wocjick. Assistance with mapping was provided by S. Prasad and C. Pene. Access to the forestry reserves was facilitated by the staff of the Colo-i-Suva Forestry Station and PWD staff. Rainfall data for the Suva area were obtained from the Fiji Meteorological Station at Laucala Bay. Special thanks to T. Koliyavu and A. Naikatini for their assistance in the field over 12 months of sampling. Finally, thanks to T. Markwell and L. Winder for help in editing this manuscript.

\section{Literature Cited}

Alcala, A. C., AND W. C. Brown. 1982. Reproductive biology of some species of Philautus (Rhacophoridae) and other Phillipine anurans. Phillipine Journal of Biology 11:203-226.

Beard, K. H., S. McCullough, and A. K. Eschtruth. 2003. Quantitative assessment of habitat preferences for the Puerto Rican terrestrial frog, Eleutherodactylus coqui. Journal of Herpetology 37:10-17.

Beebee, T. J. C. 1996. Ecology and Conservation of Amphibians. Chapman and Hall, London.

Biek, R., C. Funk, B. A. Maxell, AND L. S. Mills. 2002. What is missing in amphibian decline research: insights from ecological sensitivity analysis. Conservation Biology 16:728-734.

Fogarty, J. H., AND F. J. Vilella. 2003. Use of native forest and eucalyptus plantations by Eleutherodactylus frogs. Journal of Wildlife Management 67:186-195.

Galindo-Leal, C., J. R. Cedeno-Vazquez, R. Calderon, AND J. Augus. 2003. Arboreal frogs, tank bromeliads, disturbed seasonal tropical forest. Contemporary Herpetology 2003:1-8.

GibBons, J. R. H., AND M. L. GuineA. 1983. Observations on the development of the Fijian tree frog, Platymantis vitiensis. Herpetofauna 14:83-86.

GorHam, S. W. 1968. Fiji's frogs; life history and data from field work. Zoologische Beitrage 14:427-446.

1971. Field identification of Fiji's frogs. Fiji Agricultural Journal 33:31-33.

Gregory, P. T. 1983. Habitat structure affects diel activity pattern in the Neotropical frog Leptodactylus melanonotus. Journal of Herpetology 17: 179-181. 
Hero, J.-M., S. E. Williams, and W. E. Magnusson. 2005. Ecological traits of declining amphibians in upland areas of eastern Australia. Journal of Zoology 267:221-232.

Heyer, W. R., M. A. Donnelly, R. W. McDiarmid, L.-A. C. HAYeK, AND J. J. Foster. 1994. Measuring and Monitoring Biological Diversity-Standard Methods for Amphibians. Smithsonian Institution Press, Washington, DC.

KAM, Y.-C., AND T.-C. CHEN. 2000. Abundance and movement of the riparian frog (Rana swinhoana) in a subtropical forest of Guandau Stream, Taiwan. Zoological Studies 39:67-76.

Keppel, G., J. C. Navuso, A. Naikatini, N. T. Thomas, I. A. Rounds, T. A. Osborne, N. Batinamu, and E. SenIVASA. 2005. Botanical diversity at Savura, a lowland rainforest site along the PABITRA gateway transect, Viti Levu, Fiji. Pacific Science 59:175-191.

Laurance, W. F., T. E. Lovejoy, H. L. Vasconcelos, E. M. Bruna, R. K. Didham, P. C. Stouffer, C. Gascon, R. O. Bierregaard, S. G. Laurance, and E. Sampaio. 2002. Ecosystem decay of Amazonian forest fragments: a 22-year investigation. Conservation Biology 16:605-618.

Lehtinen, R. M. 2002. The use of screw pines (Pandanus spp.) by amphibians and reptiles in Madagascar. Herpetological Bulletin 2002:20-25.

MARSH, D. M. 2000. Variable responses to rainfall by breeding Tungara frogs. Copeia 2000:11041108.

Marsh, D. M., and P. B. Pearman. 1997. Effects of habitat fragmentation on the abundance of two species of leptodactylid frogs in an Andean montane forest. Conservation Biology 11:13231328.

Morrison, C. 2003. A Field Guide to the Herpetofauna of Fiji. Institute of Applied Sciences. University of the South Pacific, Suva, Fiji.

Parham, J. W. 1964. Plants of the Fiji Islands. Government Press, Suva, Fiji.
PARRIS, K. M. 2004. Environmental and spatial variables influence the composition of frog assemblages in sub-tropical eastern Australia. Ecography 27:392-400.

PArris, K. M., AND M. A. McCarthy. 1999. What influences the structure of frog assemblages at forest streams? Australian Journal of Ecology 24:495-502.

Pernetta, J. C., And B. Goldman. 1977. Botaniviti: the elusive Fijian frogs. Australian Natural History 18:434-437.

Pernetta, J. C., And D. Watling. 1978. The introduced and native terrestrial vertebrates of Fiji. Pacific Science 32:223-244.

RitKe, M. E., AND J. G. BАвв. 1991. Behavior of the Gray Treefrog (Hyla chrysoscleis) during the non-breeding season. Herpetological Review 22:5-8.

RYAN, P. A. 1984. Fiji amphibia. Domodomo 2:87-98. 2000. Fiji's Natural Heritage. Exisle Publishing Limited, Auckland, New Zealand.

Stewart, M. M. 1985. Arboreal habitat use and parachuting by a subtropical forest frog. Journal of Herpetology 19:391-401.

Watling, D., and G. R. Zug. 1998. Annotated List and Conservation Status of Fijian Terrestrial Reptiles and Amphibians. Fiji Biodiversity Strategy and Action Plan. Government of Fiji, Suva, Fiji.

Whitaker, D. M., A. L. Carroll, and W. A. MonTEVECCHI. 2000. Elevated numbers of flying insects and insectivorous birds in riparian buffer strips. Canadian Journal of Zoology 78:740-747.

ZuG, G. R. 1993. Herpetology: An Introductory Biology of Amphibians and Reptiles. Academic Press, San Diego, CA.

Zug, G., D. Watling, and C. Morrison. 2004. Platymantis vitiensis. In IUCN 2007. 2007 IUCN Red List of Threatened Species. Available at: www. iucnredlist.org. Accessed on 10 October, 2007.

Accepted: 9 April 2008. 